\title{
Low Back Pain and its Relationship with Working Period Among Commercial Flight Crews - An Evidence Based Case Report
}

\section{Wawan Mulyawan*, Fransiscus Januar Widjaja, Levina Chandra Khoe, Retno Wibawanti, Amilya Agustina and Syougie}

\author{
Aviation Medicine Study Program, Department of Community Medicine, Faculty of \\ Medicine, University of Indonesia, Jakarta, Indonesia \\ *Corresponding Author: Wawan Mulyawan, Aviation Medicine Study Program, \\ Department of Community Medicine, Faculty of Medicine, University of Indonesia, \\ Jakarta, Indonesia.
}

Received: June 26, 2021

Published: September 25, 2021

(C) All rights are reserved by Wawan

Mulyawan., et al.

\begin{abstract}
Flight crew has a work environment that can increase the risk of low back pain (LBP). The aim of this study is to find out whether the working period in commercial flight crews correlate with LBP. This study is an evidence-based case report, with literature searching conducted in the PubMed, Cochrane, and Ingenta databases. The inclusion criteria in the search were literatures with research subjects as crew members presenting LBP. Critical appraisal was carried out in accordance with the methods in the articles. After selecting literatures, we found three literatures based meet with the criteria. All articles use cross-sectional method. Only one study has the best quality, where the result of the study showed that there was no increase in the number of LBP sufferers within the 10-24 years of working period (Odds Ratio: 0.93 and 95\% Confidence Interval: 0.78-1.03). These evidences are still insufficient to prove that the longer working period increases the risk of LBP in commercial flight crews, due to low level of evidence.
\end{abstract}

Keywords: Pilot; Flight Attendant; Aircrew; Working Period; Flight Hour; Low Back Pain

\section{Introduction}

The World Health Organization (WHO) notes that back pain remains a leading cause of disability worldwide. ${ }^{1}$ More than onethird of back pain worldwide is attributed to occupational exposures [1]. Pain in the lower back, also called low back pain, is particularly common. Low back pain (LBP) is defined as pain or discomfort that is localized below the costal margins and above the inferior gluteal fold, either with or without referred leg pain [2]. About $60 \%$ to $90 \%$ of people will suffer from LBP at some point in their life $[3,4]$. The risk for LBP is affected by work factors for example lifting, twisting, bending, awkward movements, stretching, static postures, vibration and previous history of accident involving low back region $[4,5]$. These physical factors are considered as risk factors for drivers, dentists, office workers, and also pilots [1].

In the aeronautical environment, musculoskeletal disorders are the most common discomforts and cause of disabilities among commercial pilots, even more than cardiovascular disease [6]. It is estimated that the prevalence of back pain in pilots is close to $80 \%$ $83 \%$ [6]. The nature of LBP that appears suddenly, unpredictable, and recurs frequently, can increase the risk of incapacitation which can threaten flight safety $[3,7]$. In addition, when incapacitation oc- 
curs during an emergency, LBP can interfere with the pilot's performance in making decisions due to increased response time [8].

Aside from pilot, cabin crews are also exposed with LBP associated risk factors in flight. In a study at United States, the prevalence of LBP in cabin crew working on long-haul flights was 85,9\% [9]. With longer working period, the flight crews had longer time for the exposure, which attributed to LBP [6]. Nevertheless, there are still pros and contras about the relationship of working period and LBP $[8,10]$.

\section{Case Report}

A 43-year-old male pilot at an airline in Indonesia came to the airline's health clinic for routine visit over his low back pain that recurs often. He has experienced pain since four years ago.

He began to feel lower back pain while working in the cockpit, when he took his briefcase next to the cockpit seat. The pain remained for several days and finally he decided to go to a hospital. $\mathrm{X}$-rays of lumbar area showed within normal limits. He was given NSAIDs (non-steroidal anti-inflammatory drugs) and muscle relaxant and was also sent to physiotherapist. After undergoing medications and several physiotherapy treatments, pain were reduced, but frequently recurred. The pain was still bothersome until now, but he was able to return to normal activities. He had no history of back accident. He has been working as a pilot for five years. Previously, he had worked as a flight attendant for 16 years.

\section{Methods}

We search databases from PubMed, Cochrane, and Ingenta connect. No limitations were applied in this search. We used the following keywords for study population, i.e. "pilot*", "aviator*", "airman*”, "flyer*”, “aircrew*”, "pilot stud*”, "flight attendant*”, "purser*”, "cabin crew*", and "steward*”. While for the intervention, we used these keywords, i.e. "flight hour*", "flying hour*", "flight time*", and "years of service*". In regards to the outcome, we searched the following terms, i.e. "back pain", "backache", "lumbar pain", "lumbago", and "LBP". The inclusion criteria were articles which the research subject were flight crews presenting LBP. The exclusion criteria were articles which the research subject was military or aerospace flight crew, and articles which were literature review and letter to editor. Then, the critical appraisal would be carried out for choosing articles using critical appraisal tools. In or- der to demonstrate a good causality relationship from an etiological study, the literatures we are expected to obtain are studies with systematic review (SR), randomized controlled trial (RCT), cohort, or case-control method, which have good level of evidence.

The selection of critical appraisal tools is based on the research method applied in the articles. For studies with systematic review, we can use Assessing The Methodological Quality of Systematic Reviews (AMSTAR), Critical Appraisal Skills Program (CASP), Joanna Briggs Institute (JBI), Risk of Bias in Systematic Reviews (ROBIS), or Specialist Unit for Review Evidence (SURE). For studies with randomized controlled trial, CASP, JBI, SURE, or the Physiotherapy Evidence Database (PEDro Scale) can be used. For cohort studies we can use CASP, JBI, Scottish Intercollegiate Guidelines Network (SIGN), or The Strengthening the Reporting of Observational studies in Epidemiology (STROBE). Case-control studies may use CASP, JBI, SIGN, or STROBE. For studies with cross-sectional methods can use JBI or STROBE.

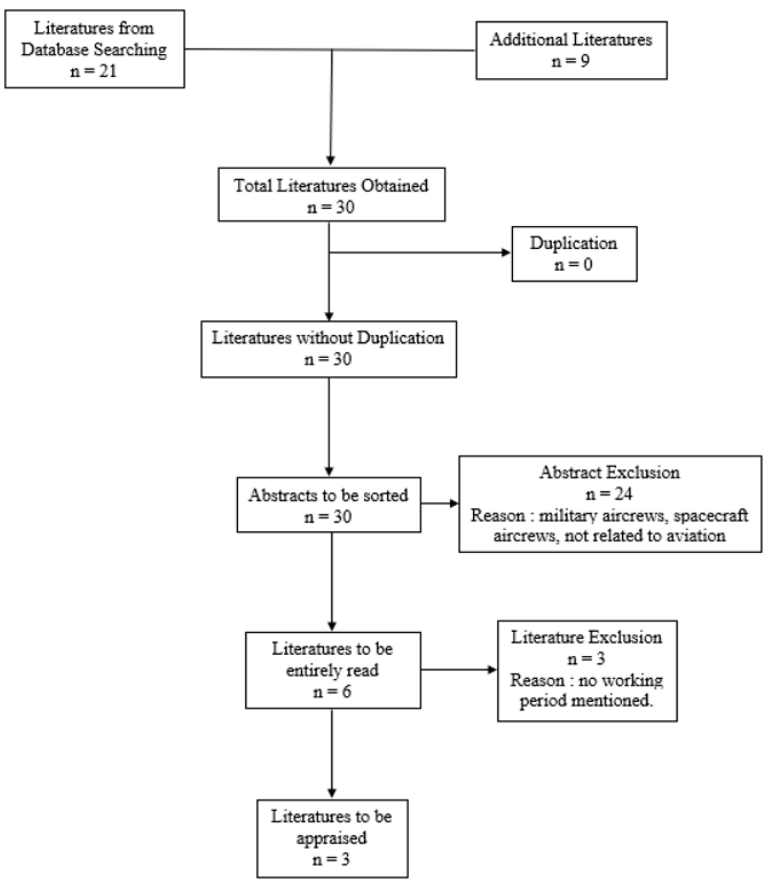

Figure 1: Prisma Flow Diagram. 


\section{Results}

The search results on June $17^{\text {th }}, 2020$ obtained 21 articles. In addition, we also searched through the bibliographies and searched using google scholars, thus obtaining 9 articles. After sorting them using the inclusion and exclusion criteria, the selected article that was subjected to critical appraisal were 3 articles. These three articles are prevalence studies applying cross sectional method. We used the assessment tools from JBI. Study characteristic can be seen at table 1 .

\begin{tabular}{|c|c|c|c|c|c|c|c|}
\hline Article & Title & Author & Published & Method & Samples & $\begin{array}{c}\text { Research Sub- } \\
\text { ject }\end{array}$ & Results \\
\hline I & $\begin{array}{l}\text { Characterization of } \\
\text { Low Back Pain in } \\
\text { Pilots and Mainte- } \\
\text { nance Technicians on } \\
\text { a Commercial Airline. }\end{array}$ & $\begin{array}{l}\text { Rodriguez., } \\
\text { et al. }\end{array}$ & 2016 & $\begin{array}{l}\text { Descriptive } \\
\text { cross-sec- } \\
\text { tional }\end{array}$ & 111 & $\begin{array}{l}\text { Pilots and ground } \\
\text { maintenance } \\
\text { technicians of a } \\
\text { commercial air- } \\
\text { line in Colombia. }\end{array}$ & $\begin{array}{l}\text { The prevalence of LBP } \\
\text { on pilots were } 71,1 \% \text {. }\end{array}$ \\
\hline II & $\begin{array}{l}\text { Lifestyles, Flying and } \\
\text { Associated Health } \\
\text { Problems in Flight At- } \\
\text { tendants. }\end{array}$ & Sharma, L. & 2007 & $\begin{array}{l}\text { Descriptive } \\
\text { cross-sec- } \\
\text { tional }\end{array}$ & 230 & $\begin{array}{l}\text { Cabin crews of an } \\
\text { airline in India. }\end{array}$ & $\begin{array}{l}\text { The prevalence of LBP } \\
\text { according to work expe- } \\
\text { rience: } \\
\text { Female FA: } \\
\text { 11-20 years : } 77,5 \% \text {, } \\
21-30 \text { years : } 79,6 \% \\
\text { Male FA : } \\
11-20 \text { years : } 65,7 \% \\
21-30 \text { years : } 67,8 \% \text {. }\end{array}$ \\
\hline III & $\begin{array}{l}\text { Flight time number } \\
\text { of sectors and risk of } \\
\text { low back pain among } \\
\text { short and medium } \\
\text { haul commercial fe- } \\
\text { male flight attendants } \\
\text { in Indonesia. }\end{array}$ & $\begin{array}{l}\text { Khrisna- } \\
\text { pandit., } \\
\text { et al. }\end{array}$ & 2016 & $\begin{array}{l}\text { Analytic } \\
\text { cross-sec- } \\
\text { tional }\end{array}$ & 240 & $\begin{array}{l}\text { Cabin crews } \\
\text { who conducted } \\
\text { routine medical } \\
\text { examination in } \\
\text { Indonesia. }\end{array}$ & $\begin{array}{l}\text { The prevalence of LBP } \\
\text { according to work } \\
\text { experience: } \\
\text { 1-5 years : } 65 \text { people } \\
6-9 \text { years : } 14 \text { people } \\
10-24 \text { years : } 12 \text { people }\end{array}$ \\
\hline
\end{tabular}

Table 1: Study Characteristic.

\begin{tabular}{|l|c|c|c|c|c|c|c|c|}
\hline & $\mathbf{Q}_{\mathbf{1}}$ & $\mathbf{Q}_{\mathbf{2}}$ & $\mathbf{Q}_{\mathbf{3}}$ & $\mathbf{Q}_{\mathbf{4}}$ & $\mathbf{Q}_{\mathbf{5}}$ & $\mathbf{Q}_{\mathbf{6}}$ & $\mathbf{Q}_{\mathbf{7}}$ & $\mathbf{Q}_{\mathbf{8}}$ \\
\hline $\begin{array}{l}\text { I (Rodri- } \\
\text { guez., et al.) }\end{array}$ & Yes & Yes & Yes & Yes & Unclear & N/A & No & N/A \\
\hline $\begin{array}{l}\text { II (Sharma, } \\
\text { L.) }\end{array}$ & Unclear & Unclear & Yes & Yes & Yes & No & No & N/A \\
\hline $\begin{array}{l}\text { III (Khrisna- } \\
\text { pandit., } \text { et } \\
\text { al.) }\end{array}$ & Yes & Yes & Yes & Yes & Yes & No & Yes & Yes \\
\hline
\end{tabular}

Table 2: Critical Appraisal Result.
In the study by Rodriguez., et al. the inclusion criteria mentioned were pilots and ground maintenance technicians who were actively working at the time of the study and were willing to give consent to participate. The exclusion criteria were those who did not complete the questionnaire. The population of research subjects were pilots and ground maintenance technicians of a commercial airline in Colombia. The time of the study was from 2011 to 2013. The length of work for pilots was measured based on the total flight hours. The data was obtained through self-filled ques- 
tionnaires. No confounding factors mentioned in this study. The final outcome measurement was carried out using a non-standardized questionnaire filled out by the participants. This final outcome measurement was less valid, because there was a risk of being underdiagnosed or overdiagnosed, and the participants were not medical personnel so that the participants' understanding of LBP may not be the same as one another. No statistical analysis was used in this study [6].

In the study by Sharma, L., it was not clear what the inclusion criteria were. However, the population of this research subject was cabin crews of an airline in India. The time period for this study was not mentioned. In this study, the measurement of work experience was the length of time they've been working as cabin crew. Confounding factors mentioned in this study were lifestyle and habits such as smoking or consuming alcohol. The researcher did not mention the strategy to overcome these confounding factors. The final outcome measurement was carried out using a non-standardized questionnaire completed by the participants. The end result that the investigators sought was back pain, not limited to the upper or lower regions. Therefore, there was a risk of being overdiagnosed. The participants were not medical personnel, so that the participants' understanding of LBP may not be the same as one another. In this study, no statistical analysis was performed [11].

In the study by Khrisnapandit., et al. the inclusion criteria were active female cabin crew, aged 19 to 45 years, and working on short and medium haul flights. The subject population of this study were female cabin crew who were undergoing routine health examination at the Indonesian Aviation Health Center, May 5-26, 2014. the measurement of work experience was the length of time they've been working as cabin crew. Confounding factors mentioned were age, education level, marital status, height, body mass index, physical activity during leisure time, smoking habit, length of work, and frequency of lifting baggage on each flight. The researcher made adjustments to several confounding factors, but not to the length of work. The final outcome was measured using the Nordic Musculoskeletal Questionnaire (NMQ), a standardized questionnaire to assess LBP. The researcher performed a multivariate analysis, so the statistical analysis used was cox regression. The analysis used is appropriate [3].

In the study by Rodriguez., et al. the researchers only mentioned the $\mathrm{p}$ value of 0.0008 , but did not mention other data so that it could not be calculated to find the odds ratio. In the study by Sharma, L. only mentioned the percentage of the prevalence of LBP in each group. Therefore, we did our own calculations to compile a $2 \times 2$ table. The odds ratio for the group of male cabin crew was 1.1 with a $95 \%$ confidence interval between 0.97 and 1.26 . The odds ratio for the group of female cabin crew was 1.09 , with a $95 \%$ confidence interval between 0.88 and 1.35 . In the study by Khrisnapandit., et al. we divided the length of work into 2 groups, $<10$ years and $\geq$ 10 years. The odds ratio was 0.93 , with a $95 \%$ confidence interval between 0.78 to 1.03 .

Our case is a pilot of a commercial airline, with a history of working as a flight attendant for 16 years. In accordance with the inclusion criteria in all three studies, our patients were not much different, and could fit into these inclusion criteria. In the study by Rodriguez., et al. there were no complete data, so calculations to find the patient's expected event rate (PEER) and number needed to harm (NNH) could not be done. The study by Khrisnapandit., et al. was conducted in Indonesia, the same country as the location of our patient. Therefore, the PEER from this literature can be used as a PEER reference for the study by Sharma, L., which was conducted in India. The PEER obtained was 0.38 , and the NNH value was -56 . In the study by Sharma, L., the NNH calculation results were 45 for male cabin crew, and 48 for female cabin crew.

\section{Discussion}

After we collect our patient's clinical data, we conducted a literature search. From the search results, there was only a small number of literatures, with low level of evidence. This limitation was caused by only few researches being carried out in aviation, especially in commercial flights. Nevertheless, there are lots of literatures that discuss LBP in military pilots. This is due to higher risk factors of LBP experienced by military pilots, such as higher workloads, higher stress level, heavier physical exercises, and using high-performance aircraft. Sitting too long, as pilots do today, can increase the risk of LBP, because the intervertebral discs have to withstand a variety of stresses, which can cause injury to the disc tissue. During sitting position, there is a posterior pelvic tilt which causes a reduction in the lumbar curvature. The upper and lower erector spinae muscles have to contract strongly to maintain an erect posture and to prevent the individual from slouching [12]. Our patient work as a flight attendant for 16 years raises our as- 
sumption that the LBP he experienced correlate with this his work history. One of the occupational risk factors of cabin crew that contributes to LBP is standing for a long time. Standing for long periods of time requires a person to maintain an erect posture which can result in muscle fatigue and ultimately leads to LBP [12].

Beside occupational factors, there are also other aviation environment factors that can contribute to LBP, such as hypoxia, cosmic radiation, changes in humidity, and G-force. The environment in the cabin of commercial aircraft is set approximately at 8,000 feet above sea level. At this altitude, the crew can still be exposed to mild hypoxia, which the oxygen saturation can reach below 95\%. Hypoxia is a condition in which there is a reduced supply of adequate oxygen to body tissues or cells [13-15]. Hypoxia also causes degenerative changes in nucleus pulposus cells inside intervertebral disc (IVD) [16.17]. Intermittent hypoxia that occurs on flights can cause systemic and intracellular changes in the human body. At the molecular level, hypoxia-induced HIF-1 $\alpha$ can help prevent degenerative processes in IVD, although there are some disagreements about this [18-20]. Overall, our patient's total length of service as flight crew was 21 years. This is certainly not a short time exposed to mild hypoxia.

The length of service for the pilot or cabin crew is calculated in units of total flight hours [21]. However, in the literatures that discuss about cabin crew, the length of service is generally calculated not using the total flight hours, but the length of time they worked as cabin crew. That was the reason our search keywords were expanded using "years of service".

The odds ratio, in the study by Sharma, L. and Khrisnapandit., et al. was close to number 1 and the confidence interval included number 1 . This indicates that there was no statistically significant difference between the longer and the shorter working periods. PEER from the study by Khrisnapandit., et al. is 0.38 , meaning that the percentage of cabin crew with a short working period (under 10 years) has an increased risk of LBP at 38\%. The NNH is -56 , which cannot be interpreted. Negative result like this can arise because of several possibilities such as the odds ratio below the number 1 , which means that longer working period is actually a protective factor against LBP. In the study by Sharma, L., NNH on a cabin crew group male is 45 , which means there is 1 person who suffers LBP out of 45 male cabin crews who work over 20 years.
And the NNH in the female cabin crew group is 48, which means there is 1 person who suffers LBP out of 48 female cabin crews who work over 20 years.

Critical appraisal result using JBI was a study by Khrisnapandit., et al. had better quality other than two studies. The study results showed that there was no increase in the number of LBP sufferers in the group that had a longer work period. These results are not in accordance with all existing theories, that there are several risk factors in flight that can cause LBP. This can be caused by various factors, such as the number of samples used.

The advantage of this evidence-based case report (EBCR) is that it can be used as an educational material for aircraft crews and aviation health personnel about the importance of preventing LBP in their environments. The weakness of this EBCR is that all the literatures obtained were not as expected to look for causality between length of work and the incidence of LBP. All of the literatures obtained were prevalence studies with low level of evidence, which do not aim to specifically seek causality.

\section{Conclusion}

In conclusion, there is no strong evidence to answer the clinical questions related to our patient: the longer working period as a pilot or flight attendant can increases the risk of LBP. We need further studies to prove whether there is a causal relationship between length of work and LBP, with better methods, such as casecontrol, cohort, randomized controlled trial, or systematic review.

\section{Bibliography}

1. Gaydos SJ. "Low back pain: Considerations for rotary-wing aircrew". Aviation, Space and Environmental Medicine 83.9 (2012): 879-889.

2. Baron R., et al. "Neuropathic low back pain in clinical practice". European Journal of Pain (United Kingdom) 20.6 (2016): 861873.

3. Khrisnapandit I., et al. "Flight time, number of sectors and risk of low back pain among short and medium haul commercial female flight attendants in Indonesia". Health Science Journal of Indonesia 7.1 (2016): 64-68. 
4. Rik L., et al. "Research on work-related low back disorders". Luxembourg, Belgium; (2000).

5. Çinar-Medeni Ö., et al. "The predictors of low back pain in helicopter pilots”. Gazi Medical Journal 26.1 (2015): 15-18.

6. Rodriguez HAF and Mayorga VAO. "Characterization of Low Back Pain in Pilots and Maintenance Technicians on a Commercial Airline". Aerospace Medicine and Human Performance 87.9 (2016): 795-799.

7. Director General of Civil Aviation. Civil Aviation Safety Regulations - Staff Instruction Part 67-02 - Manual of Aviation Medical Assessment. Ministry of Transportation, Republic of Indonesia (2018).

8. Kelley AM., et al. "Reported back pain in army aircrew in relation to airframe, gender, age, and experience". Aerospace Medicine and Human Performance 88.2 (2017): 96-103.

9. Lee H., et al. "Work-Related Musculoskeletal Symptoms Reported by Female Flight Attendants on Long-Haul Flights". Aviation, Space, and Environmental Medicine 77.12 (2006): 1283-1287.

10. Orsello CA., et al. "Height and In-Flight Low Back Pain Association Among Military Helicopter Pilots" 84.1 (2013).

11. Sharma L. "Lifestyles, flying and associated health problems in flight attendants". Journal of the Royal Society for the Promotion of Health 127.6 (2007): 268-275.

12. Pillai D and Haral P. "Prevalence of Low Back Pain in Sitting Vs Standing Postures in Working Professionals in the Age Group of 30-60". International Journal of Health Sciences and Research 8.10 (2018): 131.

13. Gradwell D. "Ernsting's Aviation and Space Medicine 5E". 49 (2016): 132.

14. Nesthus TE., et al. "Effects of mild hypoxia on pilot performances at general aviation altitudes" (1997).

15. Saputra NM., et al. "Pengaruh Paparan Zona Ketinggian Terhadap Fungsi Visuospasial Pada Awak Terbang Yang Mengikuti Indoktrinasi Dan Latihan Aerofisiologi" (2019).

16. Hiyama A., et al. "Hypoxia activates the notch signaling pathway in cells of the intervertebral disc: Implications in degen- erative disc disease". Arthritis and Rheumatology 63.5 (2011): 1355-1364.

17. Ma K., et al. "Mechanisms of endogenous repair failure during intervertebral disc degeneration". Osteoarthritis and Cartilage 27.1 (2019): 41-48.

18. Li H., et al. "Regulatory Role of Hypoxia Inducible Factor in the Biological Behavior of Nucleus Pulposus Cells". Yonsei Medical Journal 54.4 (2013): 807-812.

19. Prabhakar N., et al. "Intermittent Hypoxia: Cell To System: Eb2001 Symposium Report”. American Journal of PhysiologyLung Cellular and Molecular Physiology 25.3 (2001): 524-528.

20. Zhang F., et al. "High altitude increases the expression of hypoxia-inducible factor $1 \mathrm{a}$ and inducible nitric oxide synthase with intestinal mucosal barrier failure in rats". International Journal of Clinical and Experimental Pathology 8.5 (2015): 5189-5195.

21. International Civil Aviation Organization (ICAO). Manual of Civil Aviation Medicine. 3rd. The Secretary General of International Civil Aviation Organization (2012).

Volume 5 Issue 10 October 2021

(C) All rights are reserved by Wawan Mulyawan., et al. 